\title{
Non-invasive measurement of the regurgitant fraction by pulsed Doppler echocardiography in isolated pure mitral regurgitation
}

Department of Cardiology, South Hospital, University of Picardie, Amiens; France

C Tribouilloy

W F Shen

M A Slama

H Dufossé

D Choquet

A Marek

J-P Lesbre

Correspondence to Professor Jean-Philipp Lesbre, Service de Cardiologie B, Hôpital Sud 80000 Amiens cedex, France. Accepted for publication 8 May 1991

\author{
Christophe Tribouilloy, Wei Feng Shen, Michel A Slama, Hervé Dufossé, \\ Dominique Choquet, Alain Marek, Jean-Philippe Lesbre
}

\begin{abstract}
Objective-To assess the usefulness of pulsed Doppler echocardiography as a method of measuring the regurgitant fraction in patients with mitral regurgitation.

Patients and methods-Twenty controls and 27 patients with isolated mitral regurgitation underwent Doppler studies. In the patients the study was performed within 48 hours of cardiac catheterisation. Aortic outflow was measured in the centre of the aortic annulus, and mitral inflow was derived from the flow velocity at the tip of the leaflets and the area of the elliptical mitral opening. The regurgitant fraction was calculated as the difference between the two flows divided by the mitral inflow.

Results-In the 20 controls the two flows were almost identical (mitral inflow, 4.44 (SD 0.88) 1/min; aortic outflow, 4.58 (SD 0.84$) 1 / \mathrm{min}$ ), with a mean regurgitant fraction of $4 \cdot 2$ (SD $8 \cdot 4) \%$. In patients with mitral regurgitation, the mitral inflow was significantly higher than the aortic outflow (8.8 (3.6) v 4.3 (1.1) $1 / \mathrm{min})$. In most patients the Dopplerderived regurgitant fraction (45.8 $(19 \cdot 2) \%$ accorded closely with the regurgitant fraction $(41.3$ (SD $17 \cdot 8) \%$ ) determined by the haemodynamic technique.

Conclusion-Pulsed Doppler echocardiography, with an instantaneous velocity-valve area method for calculating mitral inflow, reliably measured the severity of regurgitation in patients with mitral regurgitation.
\end{abstract}

Both flow mapping of regurgitant jets by pulsed Doppler echocardiography and planimetry of jet area by Doppler colour flow imaging in the left atrium during ventricular systole have been used to evaluate the degree of mitral regurgitation. ${ }^{12}$ These approaches, however, give semiquantitative rather than actual volumetric assessments of regurgitation. ${ }^{3}$ Recent studies have examined the validity of pulsed Doppler method for measuring the regurgitant fraction based on the aortic and mitral flows. ${ }^{4-6}$ Despite satisfactory correlations between Doppler and haemodynamic results, the accuracy and reliability of measuring regurgitation remain uncertain, because mean flow velocity and mitral valve area are used to determine mitral inflow. We used an instantaneous velocityvalve area method to measure mitral inflow, and we compared the Doppler-derived regurgitant fraction with that obtained by a combined haemodynamic-angiographic method.

\section{Patients and methods \\ PATIENTS}

We studied 31 patients who had echocardiographic examination and cardiac catheterisation. Four patients were excluded because of poor echogenicity and the remaining 27 patients formed the study population. There were 13 men and 14 women with mean age of 57 (SD 17, range 29-81) years. All had angiographically documented isolated and pure mitral regurgitation. The cause of mitral regurgitation was mitral prolapse in 14 , rheumatic fever in two, endocarditis in two, rupture of chordae tendineae in five, and dilated cardiomyopathy in four. Twenty four patients were in sinus rhythm and three in atrial fibrillation.

Valvar regurgitation was excluded by clinical and Doppler echocardiographic examinations in 20 controls ( 15 men and 5 women, mean age 35 (SD 11, range 24-42) years. All were in sinus rhythm.

ECHOCARDIOGRAPHY

The ultrasound examination was performed with a Hewlett-Packard (mode 77020 A) Doppler imaging system. A $2.5 \mathrm{MHz}$ transducer was used for $M$ mode, cross sectional, and pulsed Doppler examinations. The filter was set : at $400 \mathrm{~Hz}$. All measurements and calculations were done by an observer without knowledge of haemodynamic data.

\section{Aortic outflow measurement}

The diameter of the aortic annulus was determined in the left parasternal long axis view just proximal to the point of insertion of the aortic cusps during midsystole. The aortic surface area was calculated by assuming a circular geometry. The aortic flow velocity was measured by pulsed Doppler method in the apical five chamber view, placing the sample volume at the level of the aortic annulus. The time-velocity integral, a product of mean velocity and ejection time, was calculated by directly tracing the area under the instantaneous velocity curve on the screen. The aortic 
outflow was derived as the product of aortic surface area times velocity integral and heart rate. ${ }^{7}$ In our laboratory, a previous study of 22 patients without valvar regurgitation showed that aortic outflow determined by pulsed Doppler method was almost identical with cardiac output measured by thermodilution technique. $^{8}$

\section{Mitral inflow measurement}

The mitral inflow was determined on the assumption that the mitral orifice was ellipsoid. ${ }^{9}$ The long axis of the mitral orifice (equivalent to the diameter of the mitral annulus) was assessed at the insertion of the mitral leaflets during middiastole in the apical four chamber view and was assumed to be constant during diastole. The short axis of the mitral orifice, which changed with time, was measured by digitising the innermost contour of representative mitral valve leaflets on $M$ mode echocardiograms recorded in left parasternal long axis or short axis views with a paper speed of $100 \mathrm{~mm} / \mathrm{s}$. The instantaneous mitral valve area was equal to $(\pi / 4) \times \mathrm{L} \times \mathrm{S}(\mathrm{t})$, where $\mathrm{L}$ is the mitral long axis and $S(t)$ the mitral short axis. The mitral flow velocity was measured by pulsed Doppler method under cross sectional guidance in an apical four chamber view; the sample volume was positioned just at the tip of the mitral leaflets (fig 1). The angle of incidence between mitral flow vector and ultrasound beam was always placed as close to zero as possible to avoid underestimation of the peak flow velocity. A representative mitral Doppler velocity curve with fully delineated mitral envelope (with clear opening and closing points) was selected to measure instantaneous mitral flow velocity.

Figure 1 Determination of mitral inflow by an instantaneous velocityvalve area method. The diameter of the mitral annulus $(L)$ in the apical four chamber view was used as the long axis of the mitral valve $(A)$. The short axis of the mitral orifice was measured by digitising the innermost contour of representative mitral valve leaflets on $M$ mode echocardiogram $(\boldsymbol{B})$ The instantaneous mitral valve area was derived from constant long axis $(L)$ and varying short axis $(S(t))$, assuming that the area was ellipsoid. The mitral flow velocity curve recorded at the tip of the mitral leaflets was digitised to measure instantaneous velocity ( $C$ and $D)$. The mitral stroke volume was the product of the instantaneous valve area and instantaneous velocity. The mitral inflow was calculated as the product of mitral stroke volume and heart rate.

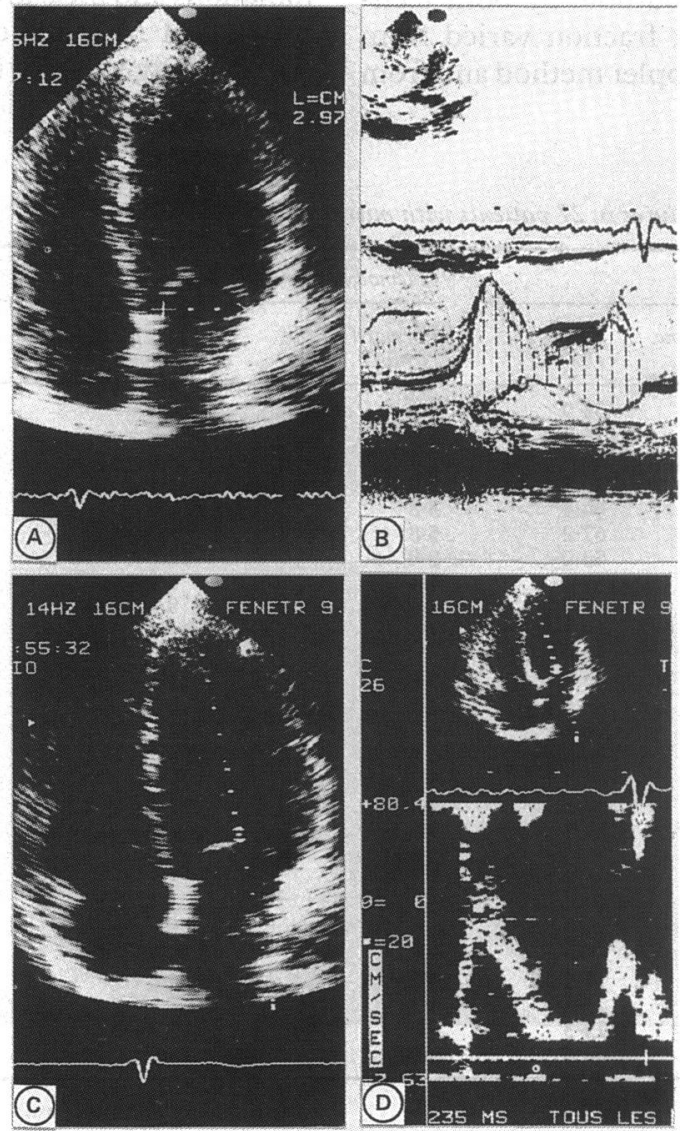

Heart rate during $M$ mode and Doppler measurements was identical. The mitral stroke volume was calculated as the product of the instantaneous valve area and instantaneous velocity. The mitral inflow was the product of the instantaneous mitral stroke volume and heart rate. We have already shown by an instantaneous velocity-valve area method that the pulsed Doppler-derived mitral inflow was almost identical to aortic outflow in 30 patients without valvar regurgitation. ${ }^{10}$

The regurgitant fraction was derived from a standard formula: regurgitant fraction $=[($ mitral inflow - aortic outflow $) /$ mitral inflow] $\times 100$.

\section{CARDIAC CATHETERISATION}

Right and left heart catherisations were performed within 48 hours of Doppler studies in all patients with mitral regurgitation. Forward cardiac output was measured by the thermodilution technique using the average of five consecutive measurements. Left ventriculography was performed in $30^{\circ}$ right anterior oblique projection, and left ventricular end diastolic and end systolic volumes were measured by the single plane area-length method. A $1 \mathrm{~cm}$ grid was filmed for correction of magnification, and the Kennedy regression equation was used to correct the overestimation of ventricular volumes. The angiographic left ventricular output (containing forward and regurgitant volumes) was calculated as the product of left ventricular stroke volume and heart rate. The heart rate was determined as an average of 10 cardiac cycles during atrial fibrillation. The regurgitant fraction was calculated as the difference between angiographic and thermodilution output divided by angiographic output and expressed as percentage.

The angiographic severity of mitral regurgitation was graded according to the method of Sellers et al. ${ }^{11}$

\section{REPRODUCIBILITY STUDIES}

We assessed the reproducibility of the method by analysing data from ten patients with coronary artery disease who were studied serially in our laboratory. These patients were selected because they did not have mitral or aortic regurgitation and because they had had two Doppler studies at an interval of two months. Both studies were performed by the same technician and the regurgitant fraction was determined as the difference between mitral and aortic flows divided by mitral flow. Reproducibility studies after a two month interval in patients with mitral regurgitation could not be performed because it could not be determined whether an observer change was real or induced by the errors of the method.

\section{STATISTICAL ANALYSIS}

Data are expressed as mean (SD). We assessed the agreement between mitral inflow and aortic outflow in normal subjects and between Doppler and haemodynamic regurgitant fraction in patients with mitral regurgitation by the method of Bland and Altman. ${ }^{12}$ 
Figure 2 Difference between Doppler measurements of aortic outflow and mitral inflow plotted against the mean value in 20 controls.

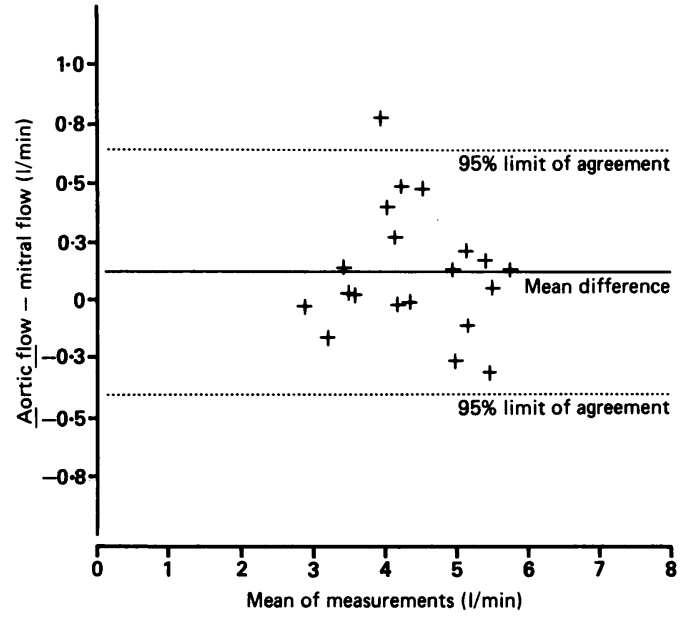

Results

CONTROLS

There was a close agreement between the mitral inflow and the aortic outflow. The $95 \%$ limits of agreement were +0.68 to $-0.421 / \mathrm{min}$ (fig 2). Themean mitral inflow and aorticoutflow were 4.44 (SD 0.88 , range $2 \cdot 99-5 \cdot 78$ ) and 4.58 (SD 0.84, range $2.96-5.91$ ) $1 / \mathrm{min}$, respectively. The difference between the two flows was $<0.6 \mathrm{l} / \mathrm{min}$ in $19(95 \%)$ of the 20 controls. The mean regurgitant fraction was $4 \cdot 2(8.4) \%$, with a regurgitant fraction of $<10 \%$ in $19(95 \%)$.

PATIENTS WITH MITRAL REGURGITATION

The table summarises the clinical, haemodynamic, and Doppler findings. There was good agreement between the Doppler and haemodynamic regurgitant fractions (fig 3). The $95 \%$ limits of agreement were -10 to $+19 \%$. The mitral inflow was significantly greater than the aortic outflow by both techniques. The regurgitant fraction varied from $11 \cdot 1$ to $73 \cdot 3 \%$ by the Doppler method and from
$8 \cdot 8$ to $67.0 \%$ by the haemodynamic method. The mean value of the regurgitant fraction measured by Doppler (45.8 (19.2)\%) was significantly higher than that measured haemodynamically $(41.3(17.8) \%)(p<0.01)$. However, in $24(89 \%)$ out of 27 patients, the difference in regurgitant fraction between the two methods was $<11 \%$. All patients with an estimated regurgitant fraction of $50 \%$ by Doppler had an angiographic grade of III or IV. The Doppler-derived regurgitant fraction was closely related to the grade of regurgitation estimated by left ventriculography (fig 4).

\section{REPRODUCIBILITY}

The mean regurgitant fraction obtained in the 10 patients with coronary artery disease during the two serial examinations was $6.9(4.5) \%$ and $6 \cdot 8(2 \cdot 7) \%$. For each patient, the difference between the two regurgitant fractions was $\leqslant 10 \%$.

\section{Discussion}

MEASUREMENT OF REGURGITANT FRACTION IN MITRAL REGURGITATION

By assessing systolic flow disturbance in the left atrium, pulsed Doppler echocardiography has been used to detect accurately the presence of mitral regurgitation and to provide a semiquantitative evaluation of its severity. ${ }^{1}$ Several studies have reported the usefulness of the Doppler method in measuring the regurgitant fraction in isolated mitral regurgitation by estimating flow volume across the mitral orifice during diastole and through aortic orifice during systole. ${ }^{46}$ Blumlein et al calculated total left ventricular output from cross sectional dimensional echocardiographic volume determinations and measured forward flow from the product of $M$ mode derived aortic valve area and the flow velocity integral in the ascending

Clinical, haemodynamic, and Doppler echocardiographic features in 27 patients with mitral regurgitation

\begin{tabular}{|c|c|c|c|c|c|c|c|c|c|c|}
\hline & \multirow[b]{2}{*}{$\begin{array}{l}\text { Age } \\
(y r)\end{array}$} & \multirow[b]{2}{*}{ Sex } & \multirow[b]{2}{*}{ Rhythm } & \multicolumn{3}{|c|}{ Doppler determination } & \multicolumn{4}{|c|}{ Haemodynamic determination } \\
\hline & & & & $\begin{array}{l}\text { Aortic flow } \\
\text { (l/min) }\end{array}$ & $\begin{array}{l}\text { Mitral flow } \\
(l / \text { min })\end{array}$ & $\begin{array}{l}R F \\
(\%)\end{array}$ & $\begin{array}{l}\text { Forward output } \\
(l / \min )\end{array}$ & $\begin{array}{l}\text { Total LV output } \\
(l / \text { min })\end{array}$ & $\begin{array}{l}R F \\
(\%)\end{array}$ & Grade \\
\hline $\begin{array}{r}1 \\
2 \\
3 \\
4 \\
5 \\
6 \\
7 \\
8 \\
9 \\
10 \\
11 \\
12 \\
13 \\
14 \\
15 \\
16 \\
17 \\
18 \\
19 \\
20 \\
21 \\
22 \\
23 \\
24 \\
25 \\
26 \\
27\end{array}$ & $\begin{array}{l}51 \\
29 \\
58 \\
63 \\
71 \\
53 \\
30 \\
59 \\
53 \\
59 \\
19 \\
64 \\
66 \\
55 \\
55 \\
76 \\
67 \\
80 \\
69 \\
17 \\
68 \\
49 \\
81 \\
50 \\
76 \\
51 \\
38\end{array}$ & $\begin{array}{l}M \\
F \\
F \\
M \\
F \\
M \\
F \\
F \\
F \\
F \\
F \\
F \\
F \\
M \\
M \\
M \\
M \\
M \\
F \\
M \\
F \\
M \\
F \\
M \\
F \\
M \\
F\end{array}$ & $\begin{array}{l}\text { Sinus } \\
\text { Sinus } \\
\text { Sinus } \\
\text { Sinus } \\
\text { AF } \\
\text { Sinus } \\
\text { Sinus } \\
\text { Sinus } \\
\text { Sinus } \\
\text { AF } \\
\text { Sinus } \\
\text { Sinus } \\
\text { Sinus } \\
\text { Sinus } \\
\text { Sinus } \\
\text { Sinus } \\
\text { Sinus } \\
\text { Sinus } \\
\text { AF } \\
\text { Sinus } \\
\text { Sinus } \\
\text { Sinus } \\
\text { Sinus } \\
\text { Sinus } \\
\text { Sinus } \\
\text { Sinus } \\
\text { Sinus }\end{array}$ & $\begin{array}{l}7 \cdot 1 \\
4 \cdot 0 \\
2 \cdot 2 \\
3 \cdot 3 \\
3 \cdot 2 \\
4 \cdot 5 \\
5 \cdot 1 \\
2 \cdot 7 \\
5 \cdot 1 \\
4 \cdot 0 \\
5 \cdot 1 \\
3 \cdot 6 \\
4 \cdot 4 \\
5 \cdot 4 \\
5 \cdot 0 \\
3 \cdot 4 \\
5 \cdot 0 \\
3 \cdot 9 \\
3 \cdot 9 \\
4 \cdot 5 \\
3 \cdot 1 \\
4 \cdot 6 \\
3 \cdot 2 \\
4 \cdot 0 \\
4 \cdot 0 \\
4 \cdot 0 \\
7 \cdot 1\end{array}$ & $\begin{array}{r}10.9 \\
4.7 \\
5.0 \\
6.2 \\
9.0 \\
13.7 \\
10.9 \\
6.6 \\
8.7 \\
13.2 \\
13.6 \\
10.4 \\
10.6 \\
10.0 \\
7.1 \\
5.8 \\
8.0 \\
8.5 \\
7.2 \\
5.3 \\
4.1 \\
5.2 \\
9.4 \\
4.5 \\
5.5 \\
15.0 \\
18.0\end{array}$ & 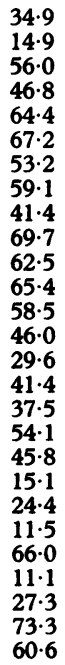 & $\begin{array}{l}6 \cdot 6 \\
5 \cdot 3 \\
2 \cdot 4 \\
5 \cdot 0 \\
3 \cdot 8 \\
5 \cdot 8 \\
8 \cdot 0 \\
4 \cdot 4 \\
7 \cdot 9 \\
4 \cdot 6 \\
6 \cdot 5 \\
3 \cdot 8 \\
4 \cdot 7 \\
5 \cdot 7 \\
4 \cdot 5 \\
5 \cdot 5 \\
4 \cdot 4 \\
3.9 \\
2 \cdot 2 \\
4 \cdot 2 \\
3.2 \\
5 \cdot 2 \\
2.5 \\
4 \cdot 2 \\
4.7 \\
4 \cdot 6 \\
9 \cdot 0\end{array}$ & $\begin{array}{r}8.9 \\
5.9 \\
4.8 \\
12.1 \\
8.6 \\
13.3 \\
12.6 \\
8.9 \\
9.8 \\
11.6 \\
15.9 \\
11.5 \\
10.7 \\
10.9 \\
6.2 \\
8.5 \\
7.5 \\
7.0 \\
3.8 \\
5.5 \\
3.9 \\
5.7 \\
5.7 \\
4.8 \\
7.1 \\
12.2 \\
18.0\end{array}$ & $\begin{array}{r}25 \cdot 8 \\
10 \cdot 2 \\
50 \cdot 0 \\
58 \cdot 7 \\
55 \cdot 8 \\
56 \cdot 4 \\
36 \cdot 5 \\
50 \cdot 6 \\
19 \cdot 4 \\
60 \cdot 3 \\
59 \cdot 1 \\
67 \cdot 0 \\
56 \cdot 1 \\
47 \cdot 7 \\
27 \cdot 4 \\
35 \cdot 3 \\
41 \cdot 3 \\
44 \cdot 3 \\
42 \cdot 1 \\
23 \cdot 6 \\
17 \cdot 9 \\
8 \cdot 8 \\
56 \cdot 1 \\
12.5 \\
33 \cdot 8 \\
62 \cdot 3 \\
50 \cdot 0\end{array}$ & $\begin{array}{l}\text { II } \\
\text { I } \\
\text { III } \\
\text { III } \\
\text { III } \\
\text { III } \\
\text { III } \\
\text { III } \\
\text { III } \\
\text { III } \\
\text { IV } \\
\text { IV } \\
\text { IV } \\
\text { III } \\
\text { II } \\
\text { II } \\
\text { II } \\
\text { IV } \\
\text { III } \\
\text { I } \\
\text { II } \\
\text { I } \\
\text { IV } \\
\text { I } \\
\text { II } \\
\text { IV } \\
\text { IV }\end{array}$ \\
\hline
\end{tabular}


Figure 3 Difference between Doppler and haemodynamic measurements of regurgitant fraction $(R F$ plotted against the mean value.

Figure 4 Relation between the Dopplerderived regurgitant fraction $(R F)$ and the angiographic grade of mitral regurgitation. The correlation coefficient for linear regression is 0.92 $(p<0.001)$. Mean (SD) of Doppler measurements is plotted for each angiographic grade.

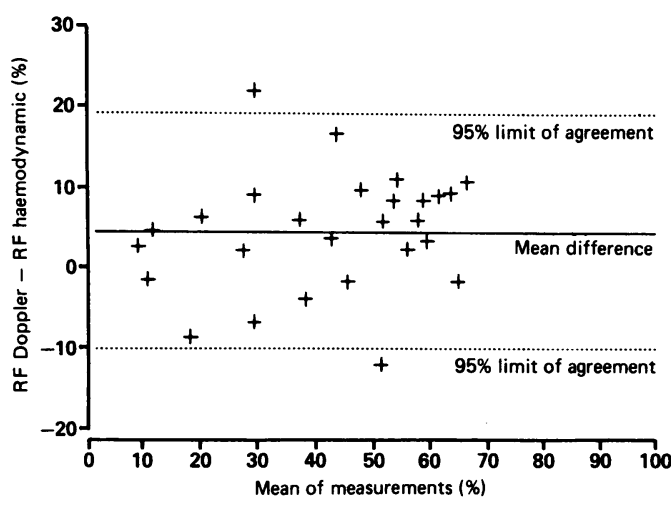

error in estimation of regurgitant fraction may be exaggerated from small errors in the stroke volume determination across the mitral valve. ${ }^{3}$

The instantaneous velocity-valve area method that we used integrates the mitral flow velocity and orifice at each instant of diastole, on the assumption that only the long axis of the mitral valve orifice is temporally and spatially constant. The correlation between Doppler and haemodynamic mitral flow measurements was considerably improved when this approach was used for a wide range of stroke volume and cardiac output estimates. ${ }^{9}$ In our study the instantaneous velocity-valve area method gave almost identical mitral inflow and aortic outflow in the controls. In patients with isolated mitral regurgitation, the regurgitant fraction calculated by this method agreed closely with both the qualitative and quantitative assessments of severity of mitral regurgitation by the haemodynamic method.

POTENTIAL LIMITATIONS OF DOPPER METHOD

Considerable errors can arise from calculations of volume flow by Doppler techniques, particularly when the valve area is estimated and where two volumes need to be measured at different sites. We found some differences between the mitral inflow and the aortic outflow measured by the pulsed Doppler method in the controls when the mean regurgitant fraction was $4 \cdot 2(8 \cdot 4) \%$. There was an overlap between the regurgitant fraction measurements in the controls and the patients with mild mitral regurgitation-one control had a regurgitant fraction of $>11 \%$. This highlights an important limitation of the technique and indicates that meticulous care is necessary to ensure the quality of information being obtained. Our study differs from previous reports in which a $15 \%$ regurgitant fraction was often seen in the control group. ${ }^{4}$ Furthermore, a similar falsely high regurgitant fraction was reported in controls assessed by the haemodynamic method. ${ }^{18}$ In patients with mitral regurgitation, the mean value of the regurgitant fraction measured by the Doppler method was slightly but significantly greater than when the regurgitant fraction was determined haemodynamically. Nevertheless, the present study showed a good agreement between Doppler measurement of regurgitant fraction and haemodynamic assessment of the severity of mitral regurgitation, indicating that both techniques could differentiate accurately the various grades of regurgitation in patients with mitral regurgitation.

In patients with atrial fibrillation, considerable variations in diastolic time can make estimation of the regurgitant fraction less accurate because of the impossibility of simultaneously recording Doppler and $M$ mode echocardiograms. Assessment of the regurgitant fraction is reasonably accurate if the measurement is derived from the average of several carefully time-matched cardiac cycles, though this is tedious and time-consuming.

The Doppler method of measuring regurgitation in patients with mitral regurgitation in this study may not be reliable when mitral stenosis is present and the mitral valve orifice is the regurgitant fraction was derived from the difference between mitral inflow and aortic outflow divided by mitral inflow, an accurate determination of the mitral inflow is crucial and an 
distorted. In this condition the long axis of the mitral valve is not equivalent to the diameter of the mitral annulus. The mitral valve area may be calculated from the pressure half-time of diastolic velocity or could be directly measured on cross sectional echocardiograms. ${ }^{1920}$ In patients with mixed mitral and aortic regurgitation, the severity of mitral regurgitation may be underestimated by the method because the aortic outflow is overestimated. In these patients, an accurate measure of mitral regurgitation may be obtained by measuring pulmonary flow as effective forward output and mitral inflow as total flow. ${ }^{21}$

We found that an instantaneous velocityvalve area method for calculating mitral inflow gave a reliable and accurate measure of the regurgitant fraction in isolated mitral regurgitation. Despite its limitations, the method may be useful in assessing the severity of valve disease and evaluating the effects of therapeutic interventions in patients with isolated mitral regurgitation.

1 Abbasi AS, Allen MW, De Cristofaro D, Ungar I. Detection and estimation of the degree of mitral regurgitation by rang-gated pulsed Doppler echocardiography. Circulation 1979;61:143-7.

2 Spain MG, Smith MD, Grayburn PA, Harlamert EA, De Maria AN. Quantitative assessment of mitral regurgitation by Doppler color flow imaging: angiographic and haemodynamic correlations. J Am Coll Cardiol 1989; 13:585-90.

3 Shah PM. Quantitative assessment of mitral regurgitation. $J$ Am Coll Cardiol 1989;13:591-3.

4 Rokey R, Sterling LL, Zoghbi WA, et al. Determination of regurgitant fraction in isolated mitral and aortic regurgitation by pulsed Doppler two-dimensional echocardiography. J Am Coll Cardiol 1986;7:1273-8.

5 Zhang Y, Ihlen H, Myhre E, Levorstad K, Nitter-Hauge S. Measurement of mitral regurgitation by Doppler echocardiography. Br Heart $J$ 1985;54:384-91.

6 Blumlein S, Bouchard A, Schiller NB, et al. Quantitation of mitral regurgitation by Doppler echocardiography. Circulation 1986;14:306-14.

7 Lewis JF, Kuo L, Nẹlson JG, Limacher MC, Quinones MA Pulsed Doppler echocardiographic determination of stroke volume and cardiac output: clinical validation of two methods using the apical window. Circulation 1984;10:425-31.

8 Dericbourg C, Tribouilloy C, Kugener H, Avinée P, Rey JL, Lesbre JP. Mesure non invasive du débit cardiaque par échocardiographie Doppler pulsé: corrélation avec la thermodilution. Arch Mal Coeur 1990;83:237-44.

9 De Zuttere D, Touche T, Saumon G, Nitenberg A, Prasquier R. Doppler echocardiographic measurement of mitral flow volume: validation of a new method in adult mitral flow volume: validation of a new metho

10 Tribouilloy C, Slama MA, Shen WF, et al. Determination of left ventricular inflow by pulsed Doppler echocardiography: influence of mitral orifice area and blood velocity graphy: influence of mitral orifice area and

11 Sellers RD, Levy MJ, Amplatz K, Lillehei CW. Left retrograde cardioangiography in acquired cardiac disease. Am J Cardiol 1964;14:437-42.

12 Bland JM, Altman DG. Statistical methods for assessing agreement between two methods of clinical measurement Lancet 1986;i:307-10.

13 Ascah KJ, Stewart WJ, Jiang L, et al. A Doppler-twodimensional echocardiographic method for quantitation of mitral regurgitation. Circulation 1985;72:377-83.

14 Fisher DC, Sahn DJ, Firedman MJ, Larson DJ, Allen HD. The mitral valve orifice method for noninvasive twodimensional echo-Doppler determinations of cardiac output. Circulation 1983;67:872-8.

15 Taylor DEM, Whamond JS. Velocity profile and impedance of the healthy mitral valve. In: Kalmanson $\mathrm{D}$, ed. The of the healthy mitral valve. In: Kalmanson $\mathrm{D}$, ed. The mitral valve. A pluridisciplinar

16 Ormiston JA, Shah PM, Tei C, Wong M. Size and motion of the mitral valve annulus in man. I. A two-dimensional the mitral valve annulus in man. I. A two-dimensional echocardiographic method and findir
subjects. Circulation 1981;64:113-20.

17 Dittman H, Voelker W, Karsch KR, Seipel L. Influence of sampling site and flow area on cardiac output measurements by Doppler echocardiography. $\mathrm{J} \mathrm{Am} \mathrm{Coll}$ Cardiol 1987;10:818-23.

18 Lopez JF, Hanson S, Orchard RC, Tan L. Quantification of mitral valvular incompetence. Cathet Cardiovasc Diagn 1985;11:139-52.

19 Martin RP, Rakowski H, Kleiman JH, Beaver W, London E, Popp RL. Reliability and reproducibility of twodimensional echocardiographic measurement of the stenotic mitral valve orifice area. $A m, J$ Cardio 1979;43:560-5.

20 Hatle L, Angelsen B, Tromsdal A. Noninvasive assessment of atrioventricular pressure half-time by Doppler of atrioventricular pressure half-tim

21 Kitabatake $A$, Ito $H$, Inone $M$, et al. A new approach to noninvasive evaluation of aortic regurgitant fraction by two-dimensional Doppler echocardiography. Circulation 1985;72:523-9. 